ORIGINAL PROF-2060

\title{
CARCINOMA BREAST;
}

Late presentation 'facts \& factors'.

Dr. Muhammad Ateeq, Dr. Shazia Jehan, Dr. Muhammad Abid Bashir

ABSTRACT... Objective: To evaluate the factors responsible for the late presentation of carcinoma of breast in Pakistani women. Study Design: Prospective, Cross sectional, Interventional. Setting: Women Medical Complex Sialkot and Surgical Unit II. Aziz Bhatti Shaheed (Teaching) Hospital. Nawaz Sharif medical College, University of the Gujrat. Study. Period: January 2009 to June 2012 . Results: A total of 87 patients of all age groups with carcinoma of breast were enrolled in this study. Mean age of presentation with breast cancer was 43 years. Stage III carcinoma breast was the most common presenting stage seen in $56(64.36 \%)$ women. Socio economic status, delay in presentation and diagnosis, fear of mastectomy and its social consequences found to be major factors in the late presentation of carcinoma of breast. Conclusions: There is need to launch cancer public health campaign mechanisms, should include teaching of Breast Self Examination (BSE) to patients, Clinical Breast Examination (CBE) to health workers. Strenuous efforts should be made to break the vicious cycle of late presentation, poor treatment outcome and reluctance of patients to present to health facilities because of social mindset.

Key words: Breast cancer, late presentation, Mastectomy

\section{Article Citation}

$\checkmark \quad$ Ateeq M, Jegan S, Bashir MA. Late presentation of carcinoma breast 'facts \& factors'. Professional Med J Feb 2013;20(1):006-012.

\section{INTRODUCTION}

Third world breast cancer is characterized by late presentation, occurring at relatively young ages and dismal mortality. The poor outcome has encouraged patients to patronize quacks and alternative healers. Recent reports from the developed world indicate a high association with obesity, smoking, and alcohol, habits which though not currently very popular in the third world are nevertheless increasingly accepted ${ }^{1}$.

Breast cancer is now the most common female malignancy word-wide with up to a million cases annually ${ }^{2,3}$. Areas of greatest incidence have been North America and Europe with black Africa considered an area of low incidence ${ }^{3}$. Studies from Nigeria indicate breast cancer has recently overtaken cervical cancer as the commonest female malignancy in areas of Western and Eastern Nigeria ${ }^{4}$. General worldwide mortality rates have decreased as a result of earlier detection, more favorable stage at presentation and improved management ${ }^{5}$. In the third world and in African - Americans breast cancer presents at advanced stage and with worse biologic behavior ${ }^{6,7}$. Reasons for late presentation are believed to be due to ignorance, superstition, self-denial, fear of mastectomy and unavailability of treatment facilities ${ }^{5,7,8}$.

In Pakistan scenario is exactly same as in other third world countries. A study that evaluated the histopathological features of 3,279 breast cancer cases in Pakistan revealed and corroborated that breast cancer presents differently in Pakistan in comparison to the United States and United Kingdom. In Pakistan, the mean age of diagnosis was found to be 49 , where as the mean age of diagnosis is 54 in Western countries ${ }^{9}$. The women in Pakistan presented with advanced disease at the time of diagnosis as reflected by larger tumor size $(>2 \mathrm{~cm})$ in over $93 \%$ of cases more over the tumors were of high grade suggesting the presence of aggressive fast spreading lesions. Such features of presentation correlated with poor prognosis and increased number of lymph node metastasis?.

The epidemiology of breast cancer in Pakistani women is not precisely known due to lack of an adequate tumor registry system ${ }^{10,11}$. However evidence 
suggests that in Pakistani women, breast cancer presents at a younger age as compared to the Western population ${ }^{11}$. In countries with limited resources, like Pakistan spending 2.4-3.7 \% of GDP on health ${ }^{12}$ majority of females present with advanced or metastatic breast cancer leading to poor outcome.12 Screening program based on routine mammography is not readily available in developing countries. In Pakistan clinical screening for breast cancer is availed by $9.5 \%$ of urban and $4.8 \%$ of rural females. Lack of awareness and low socioeconomic status are major reasons for late presentation of carcinoma of breast in Pakistani women $^{13}$. British Health Global Initiative (BHGl) proposes breast cancer awareness and breast self examination (BSE) as a means of early breast cancer detection in developing countries ${ }^{14}$.

Keeping in view the different national and international studies identifying the various factors responsible for the late presentation of carcinoma of the breast in the third world countries, this study was conducted to identify and assess the different factors responsible for late presentation of breast cancer, at tertiary care public sector and a private sector hospital of a developing country.

\section{MATERIAL AND METHODS}

This descriptive study was conducted jointly at one public sector and one privately based women hospital of District Gujrat and District Sialkot respectively, from February 2011 to June 2012 at Aziz Bhatti Shaheed Teaching Hospital Gujrat and from January 2009 to June 2012 at Women Medical Complex Sialkot. Aziz Bhatti Shaheed (Teaching) Hospital Gujrat (ABSTH) is a tertiary care hospital affiliated with Nawaz Sharif Medical College, University of the Gujrat. Women Medical Complex is a privately based hospital providing health care services exclusively to the women by female medical and paramedical staff. All the women patients presented with a breast lesion suspected of breast carcinoma during the study period were included in the study. All the women patients presented with breast disease symptoms that were proven to be benign clinically and by investigations were excluded from the study. Epidemiological data of the patient and clinical data of breast lesion was recorded in a preformed Performa by thorough history and examination. Malignancy was proved histologically by tissue biopsy. (FNAC, Trucut Biopsy, Excision/ Incision). Base line and different staging investigations were performed in all patients and appropriate treatment plan was formulated and offered to the patient according to stage of their disease. Socio-economic status (SES) was defined by key demographic and economic characteristics (reported in Government of Pakistan Economic Survey of Pakistan 2010-2011. Islamabad, Ministry of Finance, June 2011). The most important variable describing and classifying SES was annual household income. The literacy status was defined as educated and uneducated and further classified into primary, secondary and higher secondary education.

Data was reviewed, interpreted in terms of various epidemiological and clinical variables and, results were formulated and compared with national and international literature.

\section{RESULTS}

During the study period of three and half years, total 641 female patients with problems related to breast were entertained in both study setups. Out of total 641 patients with symptoms related to breast 87 females (13.57\%) were found to have breast malignancy. The most frequent age group of women affected with carcinoma of the breast was between 41 to 50 years $(59.77 \%)$ while the mean age was 43 years. Details are given in table $\mathrm{l}$.

Carcinoma of breast stage III was the most frequent stage of presentation seen in 61 patients (64.36\%) followed by stage IV seen in 21 (24.13\%) of cases. Presenting stage is given in Table II. 
It was observed that the illiterate women and the females with primary education level presented with advanced stage of disease. 23 and 31 patients presented in stage III, were illiterate and had education level of primary respectively. Details are given in Table III.

There was no much effect of locality either rural or urban was observed on presenting stage of the

\begin{tabular}{|l|c|c|}
\hline \multicolumn{1}{|c|}{ Age group } & No. of patients & \%age \\
\hline 20-30 years & 02 & $02.29 \%$ \\
\hline $31-40$ years & 12 & $13.79 \%$ \\
\hline $41-50$ years & 52 & $59.77 \%$ \\
\hline $51-60$ years & 12 & $13.79 \%$ \\
\hline$>60$ years & 09 & $10.34 \%$ \\
\hline Total & 87 & $100 \%$ \\
\hline
\end{tabular}

Table-I. Carcinoma Breast age group affected.

\begin{tabular}{|l|c|c|}
\hline Stage of disease & No. of patients & \%age \\
\hline Stage I & 03 & $03.44 \%$ \\
\hline Stage II & 07 & $08.04 \%$ \\
\hline Stage III & 56 & $64.36 \%$ \\
\hline Stage IV & 21 & $24.13 \%$ \\
\hline
\end{tabular}

Table-Il. Carcinoma Breast Stage at presentation

\begin{tabular}{|l|c|c|c|c|}
\hline \multirow{2}{*}{ Stage } & $\begin{array}{c}\text { Un- } \\
\text { educated }\end{array}$ & \multicolumn{3}{|c|}{ Educated } \\
\cline { 3 - 5 } & Primary & Secondary & $\begin{array}{c}\text { Higher } \\
\text { Secondary }\end{array}$ \\
\hline I & - & - & 01 & 02 \\
\hline II & 02 & 04 & 01 & - \\
\hline III & 23 & 31 & 02 & - \\
\hline IV & 07 & 14 & - & - \\
\hline
\end{tabular}

Table-III. Relationship between stage at presentation and literacy disease. 39 patients (44.82\%) out of total 87 patients presented with stage III \& stage IV were from rural area; where as $38(43.67 \%)$ were from urban area who presented with stage III and stage IV disease.

$77(88.50 \%)$ patients out of total 87 cases were presented with advanced disease. Details are given in Table IV.

Different factors affecting the stage of disease at presentation of patient with carcinoma of breast to seek medical advice are tabulated in Table V.

\begin{tabular}{|c|c|c|c|c|}
\hline \multirow{2}{*}{ Stage } & \multicolumn{4}{|c|}{ Locality } \\
\cline { 2 - 5 } & \multicolumn{2}{|c|}{ Rural } & \multicolumn{2}{c|}{ Urban } \\
\cline { 2 - 5 } & No. & \%age & No. & \%age \\
\hline I & - & - & 03 & $03.44 \%$ \\
\hline II & 03 & $03.44 \%$ & 04 & $04.59 \%$ \\
\hline III & 30 & $34.48 \%$ & 26 & $29.88 \%$ \\
\hline IV & 09 & $10.34 \%$ & 12 & $13.79 \%$ \\
\hline \multicolumn{2}{|c|}{ Table-IV. Relationship between locality and stage at } \\
\multicolumn{4}{|c|}{ presentation of Ca Breast } \\
\hline
\end{tabular}

Intraductal carcinoma of the breast was the most frequent histopathological type of the breast tumor observed in our study, it was found in $80(91.95 \%)$ out of total 87 patients. Upper outer quadrant of the breast was the most frequent site of involvement by the tumor seen in 38 (43.67\%) patients. Table VI.

Different treatment options depending upon the stage of the disease and compliance of the patient to a particular treatment plan is given in Table VI. Neo adjuvant chemotherapy for down staging followed by MRM for the tumor at stage III \& IV was the most frequent treatment plan offered to patients $75(86.26 \%)$. Out of total 75 only $23(30.66 \%)$ followed the treatment plan and 44 patients $(44.66 \%)$ disappeared and only 9 patients reported back to us with fungating mass. 


\begin{tabular}{|l|c|c|c|c|}
\hline \multirow{2}{*}{ Variable } & \multicolumn{4}{c|}{ No. \& \%age of patients and stage at presentation } \\
\cline { 2 - 5 } & Stage I & Stage II & Stage III & Stage IV \\
\hline Educated & $03(03.44 \%)$ & $05(05.74 \%)$ & $33(37.93 \%)$ & $14(16.09 \%)$ \\
\hline Uneducated & - & $02(02.29 \%)$ & $23(26.43 \%)$ & $27(31.03 \%)$ \\
\hline Rural & - & $03(03.44 \%)$ & $30(34.48 \%)$ & $09(10.34 \%)$ \\
\hline Urban & $03(03.44 \%)$ & $04(04.59 \%)$ & $26(29.88 \%)$ & $12(13.79 \%)$ \\
\hline House Wives & $01(01.14 \%)$ & $05(05.74 \%)$ & $41(47.12 \%)$ & $21(24.13 \%)$ \\
\hline Working ladies & $02(02.29 \%)$ & $02(02.29 \%)$ & $15(17.24 \%)$ & - \\
\hline H/O treatment from GP & - & $02(02.29 \%)$ & $30(34.48 \%)$ & $19(21.83 \%)$ \\
\hline H/O treatment from Gynecologist & $01(01.14 \%)$ & $03(03.44 \%)$ & $42(48.27 \%)$ & $15(17.24 \%)$ \\
\hline H/O treatment from Surgeons & - & - & $13(14.94 \%)$ & $15(17.24 \%)$ \\
\hline H/O treatment from traditional healers \& Dam Darood & - & - & $17(19.54 \%)$ & $14(16.09 \%)$ \\
\hline Influence of Grandmother / in laws & - & - & $28(32.18 \%)$ & $06(06.89 \%)$ \\
\hline Fear of mastectomy & - & $01(01.14 \%)$ & $13(14.94 \%)$ & $21(24.13 \%)$ \\
\hline Financial constraints & - & $01(01.14 \%)$ & $12(13.79 \%)$ & $05(05.74 \%)$ \\
\hline Social \& religious factors & - & $02(02.29 \%)$ & $05(05.74 \%)$ & $09(10.34 \%)$ \\
\hline
\end{tabular}

Table-V. Factors influencing the stage at presentation of Ca Breast

\begin{tabular}{|l|c|c|c|c|c|c|c|c|}
\hline \multicolumn{1}{|c|}{ Pathological type } & \multirow{2}{*}{ No. } & \multirow{2}{*}{$\%$ age } & \multicolumn{5}{c|}{ Site of breast involved } \\
\cline { 4 - 9 } & & & $\begin{array}{c}\text { Upper } \\
\text { outer }\end{array}$ & $\begin{array}{c}\text { Lower } \\
\text { outer }\end{array}$ & $\begin{array}{c}\text { Upper } \\
\text { inner }\end{array}$ & $\begin{array}{c}\text { Lower } \\
\text { inner }\end{array}$ & Center & Whole \\
\hline Carcinoma-in-situ & - & - & - & - & - & - & - & - \\
\hline Lobular carcinoma & 02 & 02.29 & - & - & - & - & - & 02 \\
\hline Intraductal carcinoma & 80 & 91.95 & 38 & 08 & 02 & 05 & 20 & 07 \\
\hline Medullary carcinoma & 02 & 02.29 & 02 & - & - & - & - & - \\
\hline Phyllodies tumor & 03 & 03.44 & - & - & - & - & - & 03 \\
\hline
\end{tabular}

\section{DISCUSSION}

The disease burdens of cancer are rarely considered for developing countries like Pakistan. Karachi Cancer Registry suggest that the age standardized annual rate of breast cancer in Pakistan is 69.1 per 100,000 , a figure equivalent to European and North American rates $^{15}$. In fact, Pakistan's population boasts the highest rate of breast cancer amongst all Asian 


\begin{tabular}{|l|c|c|c|}
\hline \multicolumn{1}{|c|}{ Treatment offered } & Patient No. \& \%age & LAMA No. \& \%age & Follow up No. \& \%age \\
\hline $\begin{array}{l}\text { Modified radical mastectomy MRM \& adjuvant } \\
\text { therapy }\end{array}$ & $09(10.34 \%)$ & $02(22.22 \%)$ & $07(77.77 \%)$ \\
\hline Neo-adjuvant therapy \& MRM & $75(86.20 \%)$ & $44(58.66 \%)$ & $23(30.66 \%)$ \\
\hline Simple mastectomy & $03(03.44 \%)$ & $02(66.66 \%)$ & $01(33.33 \%)$ \\
\hline Breast conservation surgery \& adjuvant therapy & $03(03.44 \%)$ & - & $03(100 \%)$ \\
\hline \multicolumn{2}{|r|}{ Table-VII. Treatment offered and patient's compliance } \\
\end{tabular}

countries as over 90,000 women suffer from breast cancer annually ${ }^{16}$. Specifically, the incidence of breast cancer in provinces of neighboring India is substantially lower than what is observed in Pakistan. In the Indian provinces of Barshi, Paranda and Bhum, breast cancer rates ranges from $8.7 \%$ per 100,000 per year to 28.2 per 100,000 per year in Bombay. At the Shaukat Khanum Memorial Cancer Hospital and Research Center in Lahore, breast cancer has accounted for $42 \%$ of total female malignancies treated $^{17}$. Thus; we can appreciate the anomalous burden of breast cancer experienced by Pakistan ${ }^{17}$.

In Pakistan, the mean age of diagnosis of breast cancer was found to be 49, where as the mean age of diagnosis is 54 in Western countries ${ }^{18}$ a study conducted in Eastern Nigeria during the period 19982005 , the age range was 17 to 80 years with a mean of 46.85 years. The peak age ranges were $30-39$ and 40 49. Less than $10 \%$ of patients aged less than 30 years and more than 70 years respectively. In our study peak age range was 41 to 50 years with mean age of 43 years. Our patients are of relatively younger age group which is comparable with local studies ${ }^{19}$.

In our study delay from initial notice of symptoms to hospital presentation ranged from one month to 02 years, only 11 (12.64\%) patients out of total 87 presented to health care facility within one month of appearance of symptoms. In Nigerian study $41 \%$ patients presented between 1 to 6 months of appearance of symptoms and delay ranges from 5 days to 09 years ${ }^{4}$.

The late presentation is universal among patients in the third world including Pakistan. Reasons of late presentation of carcinoma breast patients included in different studies are long distance to the hospital, lack of awareness, fear of the consequences like mastectomy and divorce, strong belief in traditional medicine, religious charlatan's poverty, poor education and fear and denial ${ }^{1}$. Almost all these factor were also found to be responsible for late presentation of breast cancer patients in our study but lack of awareness, poverty, fear of mastectomy, and strong belief on traditional methods of healing including Dam \& Darood were the most frequent factor responsible for late presentation. One unique fact that we found in our study was, in many cases patients did consulted health care provider at an early stage, even in some cases to doctors and gynecologists with breast symptoms, but neither the diagnosis was made timely nor the patients were properly guided and referred to specialized facility. Unfortunately in many cases clinical breast examination was not performed at all or performed inadequately due to many reasons. This is a very grave situation.

Social factors often underlie disease outcomes. Breast cancer in Pakistan is no exception to this general trend. Social factors such as income, level of education, cultural beliefs impact diagnosis, treatment strategies, patient's compliance, and survival in female breast cancer patients.13 In our study, socioeconomic and 
cultural impact observed in the form of patient's compliance to different treatment options offered to patients. Out of total 87 patients with breast cancer, 48(55.17\%) patients left against medical advice, they simply refused the treatment offered to them, and $44(91.66 \%)$ out 48 were those whom mastectomy was planned with adjuvant / neoadjuvant therapy .Fear of mastectomy and social consequences of mastectomy remained a major factor in late presentation, patient's compliance and disease outcome in third world countries1. Regardless, the outcome of these patients may be improved by patient education and increased availability of better health care facilities to prioritize diagnosis at an early cancer stage, the most important prognostic variable ${ }^{9}$.

Improvement in public health awareness in terms of knowledge, attitude, and practice of self breast examination prove to be very helpful in eliminating fear and motivating the women for early presentation with breast symptoms ${ }^{20,21}$. Role of female doctors, lady health workers, and nurses is very crucial, as due to religious norms female are reluctant to be examined by male doctors/ surgeon. Therefore female doctors and female paramedics should be trained to evaluate the symptoms of breast disease and know the method of clinical examination of breast so that patients with suspicious of breast cancer can be referred timely to specialized health care facility ${ }^{21}$.

Most funds by the Government and donor agencies to third world are targeted towards HIV and Hepatitis prevention campaigns. Considering the combination of social and physical factors governing the prevalence and effect of breast cancer, indubitably it is women of lower socioeconomic status who deserve greater consideration in designing interventions that aim to curb cancer mortality in Pakistan. Probably adding talks on cancer during the talks as a part of general health measures may assist in awareness and early detection of carcinoma of breast ${ }^{1,20}$.

\section{CONCLUSIONS}

Despite the global burden of breast cancer, it is still largely perceived to be a battled by women in developed countries. In Pakistan, women face the harrowing reality of breast cancer worsened by late presentation, aggressive course of disease and deleterious social mindsets. Long term solutions that include educational campaigns, improved Physician/ health provider awareness of breast cancer, equal distribution of strengthened primary health care facilities, and stress upon the importance of the breast self examination (BSE) are necessary steps in curbing breast cancer mortality in Pakistan.

\section{Copyright $@ 05$ Dec, 2012.}

\section{REFERENCES}

1. Stanley NC Anyanwu. Temporal trends in breast cancer presentation in the third world. J Exp Clin Cancer Res.2008; 27(1):17

2. Forbes JF. The incidence of cancer: the global burden, public health considerations. Semin Oncol.1997;24 (Suppl1):20-35. [Pub Med]

3. Palkin DM, Pisani P, Ferlay J. Global cancer statistics. CA Cancer J Clin. 1999;49(1):33-64.doi:10.3322/ canjclin.49.1.33.[Pub Med] [Cross Ref]

4. Solanke TF,Adebamowo CA. Report of the state of the art in Oncology in Ibadan and Ife. National Headquarters of Cancer Registries in Nigeria. UCH Ibadan;1996.

5. Lannin Dr, Mathews HF, Mitchell J, Swanson MS. Impacting cultural attitudes in African-American women to decrease breast cancer. Am J Surg. 2002;184(5): 418-423. doi: 10.1016/S0029610(02)1009-7. [Pub Med]

6. Chiedozi LC. Breast cancer in Nigeria. Cancer. 1985;55:563-567. Doi: 10.1002/1097-0142(19850 201) $55: 3<653::$ AID-CNCR2820550330>3.0.C0;26. [Cross Ref]

7. VelanoMU,Bawle U, Nathanson SD, Strand VF, Talpos GB, Szymanski W, Lewis FR, Jr. Racial differences in the presentation and surgical management of breast 
cancer. Surgery. 1999;125(4):375-379.

8. Shavers VL, Harlan LC, Stevens JL. Racial/eyhnic variation in clinical presentation, treatment, and survival among breast cancer patients under age 35 . Cancer 2003;97(1):134-147. doi: 10.1002/cncr.1105. [Pub Med]

9. Mahmood S, RanaTF, Ahmad M. Common determinants of $\mathrm{Ca}$ Breast-a-case control study in Lahore. Ann King Edward Med Coll 2006;12:227-8.

10. Kothari A S, Fentiman I S. Breast cancer in young women. Int J Clinic. Prac.2002 April;56(3):184-7.

11. Khanna R, Khanna S, Chaturvedi S et al. Spectrum of breast disease in young females: a retrospective study of 1315 patients. Indian J Pathology Microbiology,1998, Oct; 41(4):397-401.

12. World Health Organization. World Health Report 2006. Geneva, Switzerland: World Health Organization 2006.

13. Aziz Z, Sana S, Akram M, Saeed A. A Socioeconomic status and Breast Cancer survival in Pakistani women. J Pak Med Assoc 2004;54:448-53.

14. Anderson DM, Bray F, Ferlay J, Pisani P. Global cancer statistics 2002. CA Cancer J Clin 2005;55: 74-108.

15. Banning, Maggi, Haroon Hafeez, Saima Faisal, Mariam Hassan, and Ammarah Zafar. ' The impact of Culture and Sociological and Psychological issues on Muslim
Patients with Breast Cancer in Pakistan.' Cancer Nursing 32(2009):1-8.

16. Liede, Alexander, Imtiaz, Zeba Aziz, Patricia De Los Rios, Elaine Kwan, and Steven Narod. "Contribution of BRACA 1 and BRACA 2 Mutations to Breast and Ovarian Cancer in Pakistan." Am.J.Hum.Genet. 71(2002):595-606.

17. Badar, Farhana, Zia S. Faruqui Ammar Ashraf, and Najam Uddin. "Third World Issues in Breast Cancer." J Pak Med Assoc 57 (2007):137-40.

18. Siddiqui, M.S.,N. Kayani, M.S.Gill, S. Pervez, S. Muzaffar, S.A. Aziz. Z Setna, M. Israr . and S.H Hasan. "Breast Diseases: a histopathological analysis of 3279 Cases at a Tertiary Care Center in Pakistan." J Pak Med Assoc 53(2003).

19. Rana F, Younis J, Muzammil A, Rana S, Khawar S, Khan $\mathrm{U}$, et al. Breast cancer epidemiology in Pakistani women. J Coll Phys Surg Pak 1997;8:20-3.

20. Sara ljaz Gilani, Muhammad Khurram, Tooba Mazhar, et al. "Knowledge, attitude and practice of Pakistani female cohort towards breast cancer". J Pak Med Assoc. Vol.60 No.3 March 2010. 205-208.

21. Muhammad Naeem, Nadim Khan, Zahid Aman et al. Pattern of Breast Cancer: Experience at Lady Reading Hospital, Peshawar. J.Ayub Med Coll Abbottabad, 2008; 20(4): 22-25.

\section{AUTHOR(S):}

1. DR. MUHAMMAD ATEEQ

Associate Professor

Surgery Nawaz Sharif Medical College

(University of Gujrat) Gujrat

2. DR. SHAZIA JEHAN

Assistant Professor Surgery

Islam Medical \& Dental College, Sialkot

3. DR. MUHAMMAD ABID BASHIR

Professor of Surgery

Nawaz Sharif Medical College

(University of Gujrat) Gujrat
Correspondence Address:

Dr. Muhammad Ateeq

Associate Professor Surgery

Nawaz Sharif Medical College University of Gujrat mateeq95@yahoo.com 